University of Warwick institutional repository

This paper is made available online in accordance with

publisher policies. Please scroll down to view the document itself. Please refer to the repository record for this item and our policy information available from the repository home page for further information.

To see the final version of this paper please visit the publisher's website. Access to the published version may require a subscription.

Author(s): Matthew Watson

Article Title: The Split Personality of Prudence in the Unfolding

Political Economy of New Labour

Year of publication: 2009

Link to published version: http://dx.doi.org/ 10.1111/j.1467-

923X.2008.00960.x

Publisher statement: The definitive version is available at www3.interscience.wiley.com 


\title{
The Split Personality of Prudence in the Unfolding Political Economy of New Labour
}

\author{
Matthew Watson \\ Department of Politics and International Studies \\ University of Warwick \\ Coventry, CV4 7AL
}

matthew.g.watson@warwick.ac.uk

Published in Political Quarterly, 79 (4), 2008, 578-589. 


\section{The Split Personality of Prudence}

\section{in the Unfolding Political Economy of New Labour}

\section{Introduction}

In New Labour's hands, the concept of prudence has been used politically as part of the attempt to differentiate the current Government with its Party predecessors. According to this account of modern British economic history, all other Labour Governments have come into office overburdened by spending commitments out of all proportion to the fiscal health of the nation. By continuing to act upon such commitments, they were guilty of behaving 'imprudently', and the payback came in the form of electorally inexpedient austerity measures enforced by international currency markets in the second half of their terms. By contrast, New Labour stressed its commitment to running a tight budgetary ship whilst still in opposition, so as to avoid a punitive response from international currency markets when in government and thus protect its political momentum at the approach of the next election.

New Labour's narrative of the medium-term politics of prudence has also been internalised in the academic literature and, as a consequence, it has become the standard account. Less concern has been expressed for understanding prudence in economic terms. Specifically, no attention has been paid at all to the unfolding 
relationship between the two distinct economic definitions of the concept which have struggled for pre-eminence at various stages in the evolution of the political economy of New Labour.

The first of these definitions Gordon Brown was happy to take from his Chief Economic Advisor of the time, Ed Balls. It relates to a particular element of modern macroeconomic theory - the so-called 'time consistency problem' - and it defined the political economy of New Labour from the days of opposition all the way through its first term. I review this first aspect of Brown's 'prudence' in section one. It involves the Government's conscious manipulation of financial market expectations as a means of creating additional policy-making autonomy in the face of potentially 'corrective' movements in financial prices. The objective is to pass market tests of counterinflationary credibility by demonstrating a budgetary policy which is capable of holding national debt in check.

The second of Brown's economic definitions of prudence is much more his own, being drawn from the work of his great intellectual hero, Adam Smith. It relates to particular types of microeconomic intervention, and it has come ever more to define the political economy of New Labour beyond the end of its first term in government. Smith believed that the inculcation of prudent habits instilled in individuals a microeconomic subjectivity suited to fostering a dynamic capitalist economy. It involves encouraging individuals to save, at which point an aggregate stock of savings can be released in order to assist the process of capital accumulation. The Treasury under Brown has also been a strong advocate of institutionalising the savings habit, in particular amongst sections of the population who were previously non-savers. There are certainly good reasons for acting in such a way, with the Office for National Statistics reporting in June 2008 that British households in total now owe 
a higher proportion of their income in debt than has been the case for any other advanced economy at any point in history. ${ }^{1}$

Section three takes me to the crux of my argument. I suggest that there is a distinct chronology to Brown's appeal to the two economic definitions of prudence. The microeconomic definition (following Smith) has come to prominence only latterly during New Labour's time in office, following a substantial increase in public expenditure between 2002 and 2005. Before that, almost all emphasis was placed on the macroeconomic definition (following the time consistency problem). In many ways the turn to Smith's ideas has been used to try to paper over the cracks of the growing imprudence - as judged by the way in which New Labour previously used the concept - of the Government's own spending plans. Society has been asked to accept the burden of saving in a context in which the state is increasingly reluctant to do so.

None of this means that New Labour is necessarily wrong in its attempts to stimulate higher rates of saving within society. Given record levels of household debt, the opposite is almost certainly the case. In the absence of concerted efforts to facilitate a more widespread culture of savings, Government inaction might have increased the level of state reliance in the event that current debt burdens begin to unwind. My argument is consequently much more modest than an outright denunciation of Government savings policy. It is merely to point to the irony of the context in which the savings habit has been exhorted. Smith was adamant that trying to create within the population a dominant microeconomic subjectivity centred on the savings habit would be futile if the Government showed no restraint in its own spending plans. Yet, this is exactly what has happened in the unfolding political 
economy of New Labour. The Smithian appeal to microeconomic prudence therefore rests uneasily within the noticeably un-Smithian context in which it has been enacted.

\section{Macroeconomic Prudence}

It is necessary simultaneously to keep three different focal points in mind in order to understand the original introduction of the concept of prudence into the political economy of New Labour. The first relates to the personal influences through which Gordon Brown came to espouse the concept (i.e., from whom did he learn the significance of thinking in such a way?); the second relates to the broader climate of opinion in which the concept took on the guise of common-sense (i.e., which body of academic literature encourages the internalisation of such habits of thought?); the third relates to the specific political purpose of the Labour Party in adopting the concept (i.e., why was Brown of a mind to treat the concept as his own?). Whilst these are ostensibly three separate questions, they are integrally interwoven into a single political story.

Starting with the personal influences which lay at the heart of this story, it is clear that the primary focus should be on Ed Balls, now a member of Brown’s Cabinet as Secretary of State for Children, Schools and Families, but formerly his Chief Economic Advisor. In the earlier period he became, in effect, a veto player in the struggle for influence on Brown's thinking. From 1994, when he was first used in an advisory capacity, policies were increasingly only likely to be adopted by Brown if they met designs for fiscal propriety commensurable with the perceived wishes of investors of mobile capital operating within international financial markets. Yet this 
in itself was only ever a thinly veiled mask for whether or not they received Balls's personal seal of approval.

Balls's job as leader writer for The Financial Times had led him to develop many important contacts in the City of London, and from the soundings of these people he became convinced that Labour had to decide whether its priority was simply to win the election due some time in the five years following 1992 or to govern successfully once elected with a view to ensuring re-election. If the decision was the former then it could allow its economic policy to evolve in iterative fashion from the foundation on which it fought and lost the 1992 election. If the latter, however, it needed to develop a brand new framework of thinking appropriate to institutionalising the kind of counter-inflationary anchor which Britain had lacked through all the failed experiments with corporatism in the late 1970s, monetarism in the early 1980s, Deutschmark shadowing in the late 1980s and the European Exchange Rate Mechanism in the early 1990s. Balls invited Brown to share his enthusiasm for a decisive rupture, as opposed to incremental change, in Labour Party thinking on matters of economic policy. ${ }^{2}$

Balls has latterly revealed the extent to which his own views on the subject were shaped decisively by contributions to the theory of macroeconomic policymaking condensed in a period of rapid theoretical advancement in the two decades from the mid 1970s. ${ }^{3}$ He believed that the theory itself held the key to solving Labour's problems. On this point he found a willing audience in Brown, because Balls's account of the theory chimed directly with Brown's attempts to depict New Labour as less threatening than the Party had previously seemed to the economic aspirations of Britain's middle classes. At this time, New Labour's leaders relied heavily on focus group findings of middle-class antipathy to any kind of active tax- 
and-spend agendas in their definition of Party priorities. ${ }^{4}$ The initial political purpose of prudence was therefore to create a policy which articulated directly the perceived interests of potential floating voters amongst the middle classes, whilst simultaneously nullifying the threat of a financial market backlash against its plans.

The macroeconomic theory which informed Balls's thinking is written in the tradition of Finn Kydland and Edward Prescott's time consistency problem. Such writing depicts two potential paths for government policy. On the one hand, the government might have gained a reputation for imprudent macroeconomic policymaking, whereby the expectation takes hold amongst all economic agents that it cannot be trusted to act as diligently as it talks in support of a low-tax, low-spend agenda. All economic agents will therefore adjust their expectations to a higher-tax, higher-spend agenda irrespective of what the government actually announces, and in that move alone they will impart a higher inflationary trajectory onto the economy and consequently undermine the government's social programme. On the other hand, the government might have gained a reputation for prudent macroeconomic policymaking, whereby it will not be blown off course by economic agents' assumptions that it will subsequently follow a more expansionary policy than the one it originally announced. In this way it will gain the assent of the financial markets for pursuing its social programme. ${ }^{5}$

The theory supposes that the short-cut to such a favourable reputation lies in the creation of institutional lock-ins which demonstrate, by their very presence, that no alternatives are possible to the pre-announced policy. The decision to grant operational independence on interest rate settings to the Bank of England should be considered in this light, as should Brown's constant reiteration of strict fiscal rules designed to limit expectations of spending increases. The former creates a formal 
apparatus which, from the government's perspective, runs policy on automatic pilot, whilst the latter was intended to show that budgetary control was at least locked-into Brown’s mind.

There is a single intellectual move in the theory which makes it suitable as a means of simultaneously articulating both New Labour's political and its economic priorities. This is the treatment of inflation as a de facto tax on consumption possibilities. A consequentialist logic is offered in justification of such a move. Taxes lead to a direct loss of purchasing power at any given level of wealth, and inflation can be inferred to have an analogous effect through its impact on general product prices. From this perspective, inflation can be thought of as an implicit wealth tax, and New Labour did much in opposition to instil the sense in Britain's middle classes that they would be subjected to no new wealth tax of this nature, just as surely as they would be subjected to no new direct taxes. The macroeconomic understanding of prudence was therefore strategically aligned to perceptions of middle-class interests: every time the ostensibly technical language of the time consistency problem was used it was a direct appeal to the politics of accommodating the policy preferences associated with middle-class interests.

The academic literature on macroeconomic theory suggests that governments have a much better chance of being successful policy-makers if their 'credibility' is not in doubt. Yet, when proclaiming their own prudential virtues, such credibility has a very narrow meaning. Economically it is restricted to meeting nothing other than inflation targets, so the previously presumed trade-off between inflation and unemployment is replaced by a singular focus on inflation. Politically it restricts the terrain of feasible electoral strategies solely to the struggle for middle-class support for the party's tax-and-spend approach. The government enjoys gains to its counter- 
inflationary credibility in direct proportion to the size of the adverse effects on its social programme it is willing to ignore in order to preserve the integrity of its inflation commitments. The route to a reputation for prudent management of the economy certainly passes through talking tough about inflation, but it is whether or not the government is prepared to act tough which matters most. The key to understanding New Labour's macroeconomic understanding of prudence lies in its initially radical embrace of governance structures which deny the very logic of alternative forms of action. Such a realisation has invited any number of different characterisations of New Labour's macroeconomics, perhaps the unkindest of which is that it bettered the performance of all previous Labour Governments by betraying its core working class constituencies even before getting into office. Rather less pejorative characterisations focus on New Labour's willingness to position itself within a basically Thatcherite political settlement, thus endorsing many of the tenets of neoliberalism. ${ }^{6}$

\section{Microeconomic Prudence}

Much of the story of the preceding section will already be well known to those who read the academic literature on the subject. Whilst the details of the link to recent developments in macroeconomic theory are only infrequently revealed, there are few surprises in the suggestion that New Labour adopted a placatory stance with respect to the financial markets, or in the suggestion that this also served to further embed middle-class interests in the prevailing tax-and-spend agenda. What has not been adequately appreciated so far, however, is that there has been a second, entirely 
different conception of prudence which has been increasingly evident in policy as New Labour entered its second and now third terms of government.

The accounts of the journalists who have enjoyed prime access to Gordon Brown during his time as both Shadow Chancellor and Chancellor suggest that the attempt to run macroeconomic policy on a series of automatic pilots fits well with his personal view that macroeconomics is in any case less important than microeconomics. The second conception of prudence in evidence in Brown's management of the economy focuses on the microeconomic imperative of changing individual behavioural traits. It is taken from the work of Brown's declared favourite political economist and fellow son of Kirkcaldy, Adam Smith. This is an influence which Brown kept almost entirely to himself during the first term heyday of the macroeconomic understanding of prudence, but which he has come to assert increasingly insistently during the second and third terms of government.

Smith's outline of the concept of prudence features more prominently in The Theory of Moral Sentiments than it does in The Wealth of Nations, but even there it is inscribed with important economic content. It describes one of his four principal virtues - the others being justice, beneficence and self-command ${ }^{7}-$ and out of the four it is the one which is most obviously oriented to the self. Acting prudently in Smith's formulation allowed every person, who in any case "is first and principally recommended to his own care", to 'better their own condition'. 8 But this does not mean that Smithian prudence is as self-serving as would be the case if it were simply an anticipation of today's notion of an intrinsically selfish homo economicus.

Smith worked with a dual conception of self-interest, much in the manner of Jean-Jacques Rousseau's distinction between 'amour de soi' (literally, love of oneself) and 'amour-propre' (self-love). The latter, amour-propre, had socially 
disintegrative capacities which Smith associated with excessive vanity, leading the individual to treat other people's interests as entirely dispensable if they did not also serve their own. The truly prudent individual aims only to satisfy the former, amour de soi, whereby taking care of the self involves initially honing one's own survivalist instincts and latterly helping to design the social institutions to guarantee everyone else's survival. Brown's increasing articulation of this, rather than the more nakedly self-serving, type of self-interest appears to be less intrinsically Thatcherite than the accommodation of middle-class interests in a basically neoliberal tax-and-spend agenda. At the very least, the microeconomic variant of prudence seems at first glance to invite fewer perfunctory comparisons between New Labour and its Thatcherite inheritance than does the macroeconomic variant.

Smithian prudence translates economically into encouragement for the individual to refrain from myopic current consumption and to prioritise saving instead. He believed that the wealth of the nation depended primarily on the proportion of employees who were engaged in productive as against non-productive labour. ${ }^{9}$ This in turn depended on money being taken out of circulation and turned into invested capital: the number of workers employed productively varies directly with the amount of capital invested from private hands. ${ }^{10}$ According to Smith, the prudent individual is the one who seeks to release capital into the productive economy. This ensures their own survival as they reap the rewards of the accumulation process; furthermore, the employment of productive labour creates a social institution capable of ensuring other people’s survival.

In the words of Edwin Cannan - a late nineteenth/early twentieth century editor of Smith's work who Giancarlo de Vivo describes as a 'loyal devotee’ throughout The Wealth of Nations Smith "treats prodigality with bourgeois contempt; 
it is a kind of mental aberration; sane men save”. ${ }^{11}$ Smith himself called upon everyone of however modest means to invest with an eye to the future, whereby "the magnificence of the person whose expence had been chiefly in durable commodities, would be continually increasing, every day's expence contributing something to support and heighten the effect of that of the following day”. He contrasted this with the situation of a person who consumes so conspicuously that there is nothing left of current income for more prudential expenditures. "No trace or vestige of the expence of the latter would remain, and the effects of ten or twenty years profusion would be as completely annihilated as if they had never existed.” 12 Faced with such a choice, and even before beginning to consider the possible link to the national economic interest, the rational individual in Smith's construction would indeed appear to have a preference for saving, as Cannan suggests.

Under Brown, the Treasury also developed a number of new initiatives aimed at facilitating saving. The most immediate cause of such policies was growing concern over the size of household indebtedness, as much of the dynamism of the British economy over New Labour's first two terms was driven by credit-based consumption. Yet, it also had a more strategic dimension. New Labour has attempted to reconfigure the underlying model of welfare provision in Britain, giving much more prominence than ever before to linking that provision to the individual ownership of assets. Within such a system, the government uses tax breaks as fiscal incentives for individuals to build up their asset-based wealth. The payback comes in the gradual withdrawal of state-sponsored welfare programmes, with individuals being required to make up the shortfall in welfare expenditure by cashing in their accumulated assets and using the money thus created to purchase their own services. 
The individual who is fully incorporated into New Labour's asset-based system of welfare exhibits Smithian prudence in both of its senses. On the one hand, the move to an asset-based system of welfare has been prefigured by explicit public recognition on the part of the Government that the state pension will become increasingly incapable of sustaining people in old age. Constructing a personal portfolio of assets in the medium-term is therefore consistent with a Rousseauian amour de soi, because it provides a means of satisfying one's long-term care needs. On the other hand, the individual who has invested soundly for the future is removed as a potential burden on residual government expenditures. This allows extra money to be made available to meet the Treasury's aim of fine-tuning the fiscal incentive structure so that it is targeted primarily at those who are currently asset-poor. ${ }^{13}$ The Government hopes that this will assist in the construction of the social institutions necessary to ensure everyone's survival in a world of asset-based welfare.

The most important intermediary points in this process pass through the realms of work and saving. In order to have the opportunity to build up a portfolio of assets in the first place one needs income, and income is typically generated via active participation on the labour market. Through programmes such as the New Deal and Working Tax Credits, the Treasury under Brown linked receipt of welfare to reintegration into the labour market and tried to ensure that people would not be penalised financially by moving off benefits back into work. To subsequently make the most of the resulting opportunity to build up a portfolio of assets one needs to be convinced of the merits of saving. To this end the Treasury has undertaken a concerted financial literacy drive in order to facilitate a savings culture, backing this with initiatives such as the Saving Gateway, which promises to match the money put aside by new savers with an equal amount from the public purse. 
This is all about changing individuals' behavioural traits, using incentives strategically to turn them into the desired form of economic agent. The model person the Government has in mind is the active worker-saver-investor, a person who knows instinctively not only to withhold a proportion of their labour market rewards from current consumption but also to use the resulting flow of funds to become the owner of high-performing assets. Alan Finlayson has described the attempt to reconstitute the economic subjectivities of ordinary people as an example of modern-day "social democratic paternalism”, ${ }^{14}$ and such a characterisation appears apt. Interestingly, its content converges closely with Smith’s conception of prudence.

\section{Linking Macroeconomic to Microeconomic Prudence}

From the above it is evident that we are faced with two completely different understandings of prudence when appraising the political economy of New Labour, one macroeconomic and the other microeconomic. The most interesting question which remains is whether or not there is an intrinsic relationship between these two different understandings.

One way in which to investigate such a possibility is as a matter of simple chronology, for it is clear that there has been a shift in the relative significance of the two in public pronouncements of New Labour's policy priorities. The early period of New Labour - which we can date to the three years in opposition following the election of Tony Blair as Party leader in 1994, plus the whole of the first term in government - saw the dominance of the macroeconomic understanding of prudence. Without apparent exception, every time Brown made reference to his prudential aims 
it was in the sense of him striving to gain a reputation for strict counter-inflationary control for both the Party and the Government. Certainly his most headline-grabbing decisions in this period both fit such a pattern. The first was the announcement before the election that the Party had no intention of revising the incumbent Conservative Government's pre-set expenditure plans, even though they represented a deliberate under-estimation of what needed to be spent to maintain existing social programmes in their current form. The second was the announcement in the first week in office that the Government would hand over responsibility for interest rate settings to the Monetary Policy Committee of the Bank of England.

The later period of New Labour - which we can date to its second and third terms in government - appears to imply something quite different. There is nothing as decisive as a single moment in which Brown switched from using the macroeconomic to the microeconomic understanding of prudence. But it is nevertheless apparent, from today's position mid-way through the third term, that he is now most likely to appeal to prudence in the Smithian sense of encouraging the character traits of the active worker-saver-investor. Something seems to have happened in the second term, as a result of which the Smithian conception of prudence gradually began to displace the time consistency conception. This was contemporaneous with Brown’s increasingly conspicuous Prime-Minister-in-Waiting phase, in which he paid more and more attention to outlining his vision for the country's future. The Kirkcaldy connection between himself and Adam Smith was increasingly cited as an intellectual influence during this phase.

Suggestive as it might be in its own terms, this chronological account also reveals something much more significant politically. The shift from a macroeconomic to a microeconomic understanding of prudence is not simply a 
reflection of changing priorities for the Government. It represents, as much as anything, the response to new economic conditions of which New Labour was itself the instigator. William Keegan has provided the most authoritative journalistic account of Brown's years at the Treasury set against the unfolding political raison d'être of strict counter-inflationary control. The macroeconomic theory based on the time consistency problem treats the search for counter-inflationary credibility as something approaching an end in itself. ${ }^{15}$ By contrast, Brown would most often cite the merits of macroeconomic prudence in its own terms before then talking about 'prudence for a purpose'. For Keegan, the Balls connection is once again central in this respect. The attraction of modern macroeconomic theory for Balls was that, once established, the credibility that the theory held so dear would enable New Labour to activate enhanced social expenditure programmes with the implied consent of the financial markets. ${ }^{16}$

It is noticeable that the timing of the transition period from the macroeconomic to the microeconomic understanding of prudence directly coincides with the timing of significant increases in public spending on the frontline welfare services in health and education. The figures make for interesting reading. During the first term, when the macroeconomic understanding was at its height, the growth of public spending as a whole averaged just $1.7 \%$ per year. ${ }^{17}$ This was not only lower than for any previous Labour Government and lower than for its immediate Conservative predecessor. It was also below the average annual rates of both economic growth and general price inflation for the same four-year period, meaning that on two separate measures it was outright contractionary in real economic terms. Public sector capital investment, so vital for maintaining the infrastructure for frontline welfare services, averaged only 0.6\% of GDP between 1997 and 2001. This 
was less than for any comparable four-year period of government in the whole history of modern British politics.

Yet, by 2003, Brown's fiscal rules concerning the conduct of government expenditure had been breached - and quite spectacularly so - amidst a plethora of new spending pledges in the areas of health and education. The current budget position in Labour’s first year in power, 1997-1998, was a deficit of $£ 1.2$ billion at 2006-2007 prices. That position improved to surpluses of $£ 25$ and $£ 27.5$ billion in 1999-2000 and 2000-2001, before subsequently declining to deficits of £18.8 and £19.9 billion in 2003-2004 and 2004-2005. This represents a turnaround on the surplus on the current budget equivalent to 3.6\% of GDP between 1999-2000 and 2004-2005. The accumulated net debt was £352.9 billion in 1997-1998, falling to $£ 312.4$ billion in $2000-2001$, before rising to $£ 499.5$ billion in $2006-2007{ }^{18}$ From these figures we are left to conclude that the gamekeeper, in effect, had turned poacher.

The shift from the macroeconomic to the microeconomic understanding of prudence has its origins in these new fiscal realities. Given the favourable economic conditions that Brown inherited when becoming Chancellor, the fiscal position was always likely to look strong by the end of New Labour's first term. Even so, the strict obedience to credibility concerns initially displayed by New Labour enabled it to emphasise that strength and to pay off a substantial proportion of the short-term national debt. ${ }^{19}$ The turnaround in public spending since that time has been financed largely through new issues of medium-term debt. On its own this would have been likely to threaten the future stability of the fiscal position. But coupled with the increasingly explicit acknowledgement of the potential for substantial future pension shortfalls, the trend from the second term onwards has been very much in the opposite 
direction to macroeconomic prudence. The shift towards the microeconomic understanding of prudence in part reflect the fact that the macroeconomic story of prudence is no longer so believable, although in part it also reflects the content of the Government’s strategy to combat the growing gap in its fiscal position.

Whilst the immediate burden of the extra spending has fallen first on the public purse, New Labour proposes to lessen its long-term effects through facilitating behavioural change at the individual level. The aim is to dissipate the long-term burden of the extra spending by requiring people to become more self-reliant when planning how best to satisfy their consumption needs in old age. The move to an asset-based system of welfare reconfigures the role of the state. Whilst residual state provision is always likely to be necessary for those who remain excluded from asset ownership, the role of the state becomes not one simply of service provider. In addition, it also needs to be actively involved in creating the conditions for individuals to begin to both think and act instinctively as savers. For Brown, the sphere of desirable economic interventions has increasingly been restricted to only those attempts as are consistent with New Labour's ideal image of individual economic subjectivity.

Such a person displays a high degree of personal economic autonomy at every stage of the life cycle, treating dependency on the wage labour process as a complement to that autonomy, but dependency on the state as an affront to it. The work ethic is to be deliberately encouraged as a means of providing the basis of personal autonomy, and individuals must be encouraged to accept responsibility for meeting their own future consumption needs. The ideal image of individual economic subjectivity therefore conforms very much to the Smithian conception of prudence outlined in the previous section. At heart, though, New Labour's growing preference 
for constituting an economy of such people is itself recognition of the increasing failure of its macroeconomic prudence. The Government is increasingly asking individuals to fill the breach by making up for shortfalls in state saving with personal saving.

\section{Conclusion}

There is much to gain by looking at 'prudence' as a distinctly two-sided phenomenon in the political economy of New Labour. It allows us to say much more than simply that the concept has been significant - which it surely has - in helping the Party to project its understanding of economic priorities into British political debates. Reviewing the shift from a macroeconomic (time consistency) to a microeconomic (Smithian) definition of prudence also enables us to demonstrate, in substantive terms, how those priorities have changed. It offers a means of providing a chronology of such changes. Importantly, it also shows how the two conceptions are causally related, as one element of the political economy of New Labour unravelled during the second term and, in the process, created the necessity of its own replacement.

There is one final twist in the tale, which suggests that the split personality of prudence might actually prove to be a double-edged sword for New Labour. The transition between the macroeconomic and the microeconomic understanding of prudence took place without any outwardly apparent process of political struggle in the Labour Party, suggesting that from the Party's perspective the latter acts very much as a substitute for the former. However, if we look at the provenance of the ideas which underpin the microeconomic understanding, a different conclusion arises. 
The microeconomic understanding has definite Smithian undertones, but Smith himself was adamant that the principles of personal prudence applied every bit as much to the state. When asked by the-then Chancellor of the Exchequer, Charles Townshend, for his advice on how best to wind down the public debt, he willingly gave it. He was, at the very least, the partial architect of a recalibration of the 'Sinking Fund', changes which Townshend introduced in 1767 as a means of balancing the borrowing necessary during war-time with accelerating surpluses during peace-time. $^{20}$ In his written work, Smith warned against the state acting as “improvident spendthrift”, suggesting that, once set on such a course, "when the wisest government has exhausted all the proper subjects of taxation, it must, in cases of urgent necessity, have recourse to improper ones”. He believed that a state persistently spending beyond its immediate needs impacted adversely on both the lives and the habits of thought of its citizens: "[W]ithout any advantage to the publick, [such spending] extends the calamity to a great number of other innocent people. It occasions a general and most pernicious subversion of the fortunes of private people; enriching in most cases the idle and profuse debtor at the expence of the industrious and frugal creditor, and transporting a great part of the national capital from the hands which were likely to increase and improve it, to those which are likely to dissipate and destroy it”. ${ }^{21}$

For Smith, the savings culture has its most profound impact at the level of individual economic subjectivity only when the state is both advocate of and adherent to that same culture. New Labour's own articulation of the need for time consistent policies and overall policy-making credibility suggests that a profligate government runs the risk of injecting new inflationary tendencies into the economy. However, an inflation-prone economy reduces the incentives to save and makes much more 
difficult the development of a savings culture. As such, the successful enactment of the microeconomic understanding of prudence appears to be dependent on the successful enactment of the macroeconomic understanding. From a Smithian perspective at least, it is not merely a substitute for it. By increasingly acting as if it was, a tension therefore looks as though it has been introduced into the political economy of New Labour. The split personality of its central concept of prudence, allied to New Labour's particular deployment of the second meaning of the concept as a masking agent for fault-lines in the first, lies at the heart of the tension. It is one of the Government's own making.

The current Conservative Opposition has made much of the claim that the credit crunch has exposed weaknesses in the Government's approach to the budget position. It is accused of not having put enough money aside when the economy was unencumbered by exogenous shocks in order to fund later counter-cyclical spending. A case can certainly be made that Brown's fiscal rules inadvertently countenanced a short-term approach to budgetary balance at the expense of the stated goal of longterm budgetary stability. Yet, this is not my main argument here, as I have attempted merely to outline the distinct intellectual provenance of New Labour's simultaneous accounts of economic prudence rather than to engage in a more thoroughgoing critique of its economic policy.

I have been concerned mainly with the way in which the Government has changed the ideational basis of its economic strategy in an attempt to ease the pressure on its budget position. As a consequence of this shift, the responsibility to save has increasingly been delegated from the state to society. If such a policy is successful, it will render increasingly secondary the question of the relationship between short-term budgetary balance and long-term budgetary stability, because the latter condition will 
be approached in the future via the savings of individuals not the state. With household debt in aggregate running at $173 \%$ of income in June 2008 - the highest figure ever recorded anywhere - there is an obvious reason for the Government's interest in initiating a more robust savings culture. However, the timing of its conversion to the microeconomic understanding of prudence shows that it only switched policy priority once it had recognised that its fiscal rules had already failed.

\footnotetext{
Notes

* I would like to thank the editors of Political Quarterly for their helpful and perceptive comments when refereeing the original draft of this article. All responsibility for content, of course, remains my own. I would also like to acknowledge the fact that the current piece draws on research undertaken with the financial assistance of a grant from the Economic and Social Research Council (number RES000-22-2198, 'Rethinking the Adam Smith Problem'). I thank the ESRC for its continuing support of my research.

${ }^{1}$ Daily Telegraph, June 28, 2008.

${ }^{2}$ On the Balls influence on Brown, see, for instance, the following: Andy McSmith, Faces of Labour: The Inside Story, London: Verso, 1997; Brian Brivati, 'Gordon Brown', in Kevin Jefferys (ed.), Labour Forces: From Ernie Bevin to Gordon Brown, London, I.B. Tauris, 2002, pp. 237-250; Richard Parry and Nicholas Deakin, 'Control through Negotiated Agreements: the Changing Role of the Treasury in Controlling Public Expenditure in Britain', in John Wanna, Lotte Jensen and J. de Vries (eds.), Controlling Public Expenditure: The Changing Roles of Central Budget Agencies - Better Guardians?, Cheltenham: Edward Elgar, 2003, pp. 106-125; Derek Scott, Off Whitehall: A View from Downing Street by Tony Blair's Adviser, London: I.B. Tauris, 2004.

${ }^{3}$ Ed Balls, 'Open Macroeconomics in an Open Economy', Scottish Journal of Political Economy, 1998, pp. 113-132.

${ }^{4}$ Two very different accounts appear in: Philip Gould, The Unfinished Revolution: How the Modernisers Saved the Labour Party, new edition, London: Abacus Books, 1999; Leo Panitch and Colin Leys, The End of Parliamentary Socialism: From New Left to New Labour, London: Verso, 1997.

${ }^{5}$ Finn Kydland and Edward Prescott, 'Rules Rather than Discretion: The Inconsistency of Optimal Plans', Journal of Political Economy, 1977, pp. 473-491; Robert Barro and David Gordon, 'Rules, Discretion, and Reputation in a Model of Monetary Policy', Journal of Monetary Economics, 1983, pp. 101-121; Kenneth Rogoff, 'The Optimal Degree of Commitment to an Intermediate Monetary Target', Quarterly Journal of Economics, 1985, pp. 1169-1189; for a review, see Allan Drazen, Political Economy in Macroeconomics, Princeton, NJ: Princeton University Press, 2000.

${ }^{6}$ See, for instance, Colin Hay, The Political Economy of New Labour: Labouring Under False Pretences?, Manchester: Manchester University Press, 1999.

${ }^{7}$ On which see, for instance, Leonidas Montes, Adam Smith in Context: A Critical Reassessment of some Central Components of His Thought, Basingstoke: Palgrave Macmillan, 2004, pp. 69-75.

${ }^{8}$ Adam Smith, The Theory of Moral Sentiments, Indianapolis, IN: Liberty Fund, 1982 [1759], VI.ii.1.1, p. 219; I.iii.2.1, pp. 50-1.

9 Adam Smith, An Inquiry into the Nature and Causes of the Wealth of Nations, Indianapolis, IN: Liberty Fund, 1981 [1776], Intro.3, p. 10.

${ }^{10}$ Smith, Wealth of Nations, II.v.22-27, pp. 367-9.
} 


\footnotetext{
${ }^{11}$ Giancarlo de Vivo, 'Adam Smith and His Books', Contributions to Political Economy, 2001, pp. 8797, p. 88; Edwin Cannan, 'Adam Smith as an Economist', Economica, 1926, pp. 123-134, reprinted in John Cunningham Wood (ed.) Adam Smith: Critical Assessments, Volume II, London: Routledge, 1993, pp. 20-28, p. 25.

${ }^{12}$ Smith, Wealth of Nations, II.iii.38, pp. 346-7.

${ }^{13}$ See, for instance, HM Treasury, Saving and Assets For All: The Modernisation of Britain's Tax and Benefit System, Number Eight, London: HM Treasury, 2001; HM Treasury, Delivering Saving and Assets: The Modernisation of Britain's Tax and Benefit System, Number Nine, London: HM Treasury, 2001; HM Treasury/Inland Revenue, Detailed Proposals for the Child Trust Fund, London: HMSO, 2003.

${ }^{14}$ Alan Finlayson, 'Characterizing New Labour: The Case of the Child Trust Fund', Public Administration, 2008, pp. 95-110, p. 98.

${ }^{15}$ Matthew Watson, The Political Economy of International Capital Mobility, Basingstoke: Palgrave Macmillan, 2007, 68-79.

${ }^{16}$ The general point is reviewed by Layna Mosley, Global Capital and National Governments, Cambridge: Cambridge University Press, 2003.

${ }^{17}$ William Keegan, The Prudence of Mr. Gordon Brown, paperback edition, Chichester: John Wiley \& Sons, 2004, p. 250.

${ }^{18}$ All the figures appearing in this paragraph are taken from the Public Finances Databank published on the website of HM Treasury.

${ }^{19}$ Keegan, The Prudence of Mr. Gordon Brown, p. 290.

${ }^{20}$ Iain McLean, Adam Smith, Radical and Egalitarian: An Interpretation for the $21^{\text {st }}$ Century, Edinburgh: Edinburgh University Press, 2006, p. 16.

${ }^{21}$ Smith, Wealth of Nations, V.iii.13, p. 912; V.iii.58, pp. 928-9; V.iii.60, pp. 929-30.
} 